\title{
Dengue Fever- New Threats from Old Enemy
}

F Ahammad

Dengue is a mosquito-borne viral infection causing a severe flu-like illness, sometimes potentially lethal complications. It is classified as a neglected tropical disease $\mathrm{e}^{1,2}$. Approximately, half of the world's population is at risk and it affects infants, young children and adults. The incidence of dengue has increased 30 -fold over the last 50 years. Up to 50-100 million infections are now estimated to occur annually in over 100 endemic countries including Bangladesh ${ }^{3}$.

The first recorded case of probable dengue fever was in a Chinese medical encyclopedia from the Jin Dynasty (265-420 AD) which referred to a "water poison" associated with flying insects. The primary vector, $A$. aegypti spread out of Africa in the $15^{\text {th }}$ to $19^{\text {th }}$ centuries due to the slave trade. The most plausible early reports of dengue epidemics are from 1779 and 1780, when an epidemic swept across Asia, Africa and North America. From that time until 1940, epidemics were infrequent. During and after the Second World War the marked spread of dengue has been attributed due to ecologic disruption ${ }^{4}$. The Aedes mosquito was confirmed as a vector in 1965. The dengue hemorrhagic fever, the severe form of the disease was first reported in the Philippines in 1953 and dengue hemorrhagic fever and dengue shock syndrome were first noted in Central and South America in $1981^{6}$.

Bangladesh has been experiencing episodes of dengue fever in every year since 2000. All four serotypes have been detected, with DENV-3 predominance until $2002^{7}$. After that, no DENV-3 or DENV-4 was reported from Bangladesh. The Institute of Epidemiology, Disease Control \& Research (IEDCR) found DENV-1 and DENV-2 in circulation (2013-2016) and predicted that because serotypes DENV-3 and DENV-4 are circulating in neighboring countries, they may create epidemics of secondary dengue in the near future. In 2017, reemergence of DENV-3 was identified; subsequently there was a sharp rise in dengue cases from the beginning of the monsoon in 2018 although the situation was controlled. In 2019 during the early monsoon dengue outbreak with death in Dhaka started in an alarming way and till $20^{\text {th }}$ October 2019 affected number are almost 90,000 and total death is 103 according to DGHS although both numbers are higher according to print and electronic media reports. The situation is highest compared to the last 16 years. Presenting features with cerebral encephalopathy, hepatic and renal failure in current epidemic is higher than past episodes counting more death. Moreover, typical presenting features like

1. Dr. Faruk Ahammad, MBBS, FCPS (Medicine), Professor, Department of Medicine. Faridpur Medical College, Faridpur.

\section{Address of correspondence :}

Dr. Faruk Ahammad, MBBS, FCPS (Medicine), Professor, Department of Medicine. Faridpur Medical College, Faridpur. Mobile: +88-01817011894, E-mail: farukahammad26@yahoo.com fever with break bone pain and rash have been changed in maximal cases with atypical features like vomiting, abdominal pain and shock. In short, the Dengue syndrome has changed its natural history which demands to update the national guideline on dengue management developed by DGHS, Bangladesh.

The virus passes to humans through the bites of an infective female Aedes mosquito, which mainly acquires the virus while feeding on the blood of an infected person. The full life cycle of dengue fever virus involves the role of mosquitoes as a transmitter (or vector) and humans as the main victim and source of infection. Once humans are infected, humans become the main carriers and multipliers of the virus; serve as a source of the virus for uninfected mosquitoes. The virus circulates in the blood of an infected person for 2 to 7 days, at approximately the same time the person develops a fever. The infected person can transmit the infection via Aedes mosquitoes after the first symptoms appear which normally occur within 4 to 5 days to maximum 12 days.

The government of Bangladesh took the major initiatives to combat the situation like opening "One-stop Dengue Helpdesk" at all hospitals, monitoring cell opened in the ministry, extending dengue service/beds in all hospitals, preparing 3 government hospitals in Dhaka for emergency dengue response, distribution of more than 42,000 dengue kit to all districts hospitals, fixing the fees of basic dengue tests for private sector, workshop on national treatment guideline, discussion on feasibility/prospect of dengue vaccine in Bangladesh, standing against misleading viral posts in social media and involving general population including medical college students in awareness campaign.

Despite all these measures with having 18 years' experience of dengue infection management, the death toll in Bangladesh is high in comparison to neighbor dengue endemic countries like Philippines: 130,463 cases, 561 deaths as of 13 July, 2019; Malaysia: 75,913 cases, 111 deaths as of 27 July, 2019; Vietnam: 115,186 cases, 12 deaths as of 21 July, 2019; Thailand: 44,671 cases, 62 deaths as of 16 July, 2019; Singapore: 8,020 cases without death as of 21 July, 2019 and in Sri Lanka: 234,078 cases, 47 deaths as of 05 Aug, $2019^{8}$.

So, attention is required for strengthening the early detection of dengue infection at all healthcare facilities and updating management guidelines, followed by training healthcare professionals. In addition, public health management like a vector control program, community awareness regarding prevention and early 
notification of febrile illness and establishment of an early warning system through surveillance platforms are of the utmost importance. To control the vector in addition to conventional insecticide spray, Wolbachia can be used which is a natural bacterium, present in almost $60 \%$ of insect species. Wolbachia helps the insects to breed but exception in Aedes aegypti. The eggs of Wolbachia infected mosquitoes can't hatch out reducing the mosquito number. Malaysia and Australia are successfully using this biotechnic replacing insecticide use. Technical committee meeting for Wolbachia project was held on 24 July, 2019 to discuss the prospect and feasibility of adopting this innovative tool in Bangladesh.

\section{References:}

1. WHO- List of neglected tropical diseases.

2. Fenwick A. "The global burden of neglected tropical diseases". Public Health 2012; 126(3): 233-36.

3. World Health Organization. 2012. Global strategy for dengue prevention and control, 2012-2020.

4. Gubler DJ. Dengue and dengue hemorrhagic fever. Clin Microbiol Rev. 1998 Jul; 11(3):480-96.

5. Henchal EA, Putnak JR. "The dengue viruses". Clinical Microbiology Reviews 2011; 3(4): 376-96.

6. Gould EA, Solomon T. Pathogenic flaviviruses. Lancet 2008; 371(9611): 500-9.

7. Shirin T, Muraduzzaman AKM, Alam AN, Sultana S, Siddiqua S. Largest dengue outbreak of the decade with high fatality may be due to reemergence of DEN-3 serotype in Dhaka, Bangladesh, necessitating immediate public health attention. New Microbes New Infect. 2019 May; 29: 100511.

8. Health Bulletin- Bangladesh Dengue Situation 2019. volume: 3, 10 August, 2019; published by CDC, DGHS. 